\title{
Biomineralization control related to population density under ocean acidification
}

\author{
Stefano Goffredo ${ }^{1 \star}$, Fiorella Pradaa ${ }^{1}$ Erik Caroselli ${ }^{1}$, Bruno Capaccioni ${ }^{2}$, Francesco Zaccanti ${ }^{1}$, \\ Luca Pasquini ${ }^{3}$, Paola Fantazzini ${ }^{3,4}$, Simona Fermani ${ }^{5}$, Michela Reggi ${ }^{5}$, Oren Levy ${ }^{6}$, \\ Katharina E. Fabricius ${ }^{7}$, Zvy Dubinsky ${ }^{6}$ and Giuseppe Falini ${ }^{5 \star}$
}

\begin{abstract}
Anthropogenic $\mathrm{CO}_{2}$ is a major driver of present environmental change in most ecosystems ${ }^{1}$, and the related ocean acidification is threatening marine biota ${ }^{2}$. With increasing $\mathrm{PCO}_{2}$, calcification rates of several species decrease ${ }^{3}$, although cases of upregulation are observed ${ }^{4}$. Here, we show that biological control over mineralization relates to species abundance along a natural pH gradient. As $\mathrm{pCO}_{2}$ increased, the mineralogy of a scleractinian coral (Balanophyllia europaea) and a mollusc (Vermetus triqueter) did not change. In contrast, two calcifying algae (Padina pavonica and Acetabularia acetabulum) reduced and changed mineralization with increasing $p \mathrm{CO}_{2}$, from aragonite to the less soluble calcium sulphates and whewellite, respectively. As $\mathrm{pCO}_{2}$ increased, the coral and mollusc abundance was severely reduced, with both species disappearing at $\mathrm{pH}<7.8$. Conversely, the two calcifying and a non-calcifying algae (Lobophora variegata) showed less severe or no reductions with increasing $\mathrm{PCO}_{2}$, and were all found at the lowest $\mathrm{pH}$ site. The mineralization response to decreasing pH suggests a link with the degree of control over the biomineralization process by the organism, as only species with lower control managed to thrive in the lowest $\mathrm{pH}$.
\end{abstract}

Several studies on the influence of $\mathrm{pH}$ on crystallography and texture of calcified regions are ex situ, short-term experiments on isolated organisms ${ }^{5}$, providing important information, but unrepresentative of natural ecosystems and failing to assess longterm effects ${ }^{6}$. There is a great need for long-term analyses on ocean acidification effects on marine ecosystems acclimated to high $p \mathrm{CO}_{2}$, as found around $\mathrm{CO}_{2}$ vents. Vents are not perfect predictors of future oceans, owing to $\mathrm{pH}$ variability, proximity of unaffected populations, and co-varying environmental parameters ${ }^{7}$. However, vents acidify sea water on sufficiently large temporal and spatial scales to integrate ecosystem processes ${ }^{6}$, acting as 'natural laboratories'. In Papua New Guinea vents, reductions in coral diversity, recruitment and abundance, and shifts in competitive interactions, are found ${ }^{8}$. In Mediterranean vents, decreased diversity, biomass, trophic complexity and abundance in many calcifying and non-calcifying organisms, and increases in macroalgae and seagrasses, are observed ${ }^{7,9,10}$

We assessed, along a natural $\mathrm{pH}$ gradient, the effect of $\mathrm{pCO}_{2}$ on the mineralization and abundances of the aragonitic scleractinian
B. europaea, the aragonitic tube-forming gastropod $V$. triqueter, the brown alga $P$. pavonica, which deposits aragonite on the thalli surface, the green alga A. acetabulum, whose cups' outer surfaces are calcified with aragonite and a small amount of whewellite (calcium oxalate), and the non-mineralized brown alga $L$. variegata. The mineralization is biologically controlled in $V$. triqueter (that is, mineral is deposited in confined nucleation sites under complete biological control with minimal environmental effects), biologically induced in $P$. pavonica and A. acetabulum (that is, it is strongly affected by the environment with minimal biological control), whereas B. europaea may represent an intermediate and still controversial situation ${ }^{11}$. We aimed to assess changes in the mineralization and abundance of species along a $p \mathrm{CO}_{2}$ gradient in relation to their control over biomineralization.

Mean $\mathrm{pH}, \mathrm{CO}_{2}$, saturation of calcite $\left(\Omega_{\text {calc }}\right)$, and of aragonite $\left(\Omega_{\text {arag }}\right)$ differed among Sites (Kruskal-Wallis test/analysis of variance, $p<0.001$ ). The median $\mathrm{pH}$ values were 8.1 (Site 1 ), 7.9 (Site 2), 7.8 (Site 3) and 7.7 (Site 4), with increasing variability towards Site 4 (Fig. 1 and Supplementary Fig. 1 and Table 1).

Aragonite was the only mineral phase in B. europaea skeletons (Supplementary Fig. 2). Organic matrix content was homogeneous among Sites (Kruskal-Wallis test, $p>0.05$; Supplementary Fig. 3 and Table 1). Skeletal texture exhibited fibres evolving from a centre of calcification (Supplementary Fig. 4), but the morphology of these centres, and fibre thickness $(600 \pm 200 \mathrm{~nm})$, were not related to $p \mathrm{CO}_{2}$ (Supplementary Fig. 5). Hardness was homogeneous among sample regions and study Sites $(5100 \pm 600 \mathrm{MPa})$. The elastic Young's modulus decreased (that is, the skeleton became less stiff) along the aboral to oral direction and was lower at Sites 2 and 3 than at Site 1 (Supplementary Table 2). Crystal quality and fibre thickness usually increases when crystallization occurs under lower supersaturation $^{12}$. Although a reduction of precipitation rate with $p \mathrm{CO}_{2}$ could increase crystal quality, other mechanisms could involve organic matrix molecules. Corals seem to maintain a high $\mathrm{pH}$ at the nucleation sites within the calicoblastic layer, possibly expending a significant amount of energy ${ }^{13}$. This is supported by the lack of increase in aragonite fibre thickness with decreasing seawater $\Omega_{\text {arag, }}$, which would be expected if $\Omega_{\text {arag }}$ of the calcification site decreased ${ }^{12}$. The reduction of skeletal stiffness with declining $\mathrm{pH}$ is probably associated with an increase in porosity, as confirmed by preliminary

\footnotetext{
${ }^{1}$ Marine Science Group, Department of Biological, Geological and Environmental Sciences, Section of Biology, Alma Mater Studiorum - University of Bologna, Via F. Selmi 3, 40126 Bologna, Italy, ${ }^{2}$ Department of Biological, Geological and Environmental Sciences, Section of Geology, Alma Mater Studiorum - University of Bologna, Piazza di Porta S. Donato 1, 40127 Bologna, Italy, ${ }^{3}$ Department of Physics and Astronomy, Alma Mater Studiorum University of Bologna, Viale Berti Pichat 6/2, 40127 Bologna, Italy, ${ }^{4}$ Centro Enrico Fermi, Piazza del Viminale 1, 00184 Rome, Italy, ${ }^{5}$ Department of Chemistry 'G. Ciamician', Alma Mater Studiorum - University of Bologna, Via F. Selmi 2, 40126 Bologna, Italy, ${ }^{6}$ The Mina and Everard Goodman Faculty of Life Sciences, Bar-Ilan University, 52900 Ramat-Gan, Israel, 7 Australian Institute of Marine Science, PMB 3, Townsville 4810, Queensland, Australia. *e-mail: s.goffredo@unibo.it; giuseppe.falini@unibo.it
} 

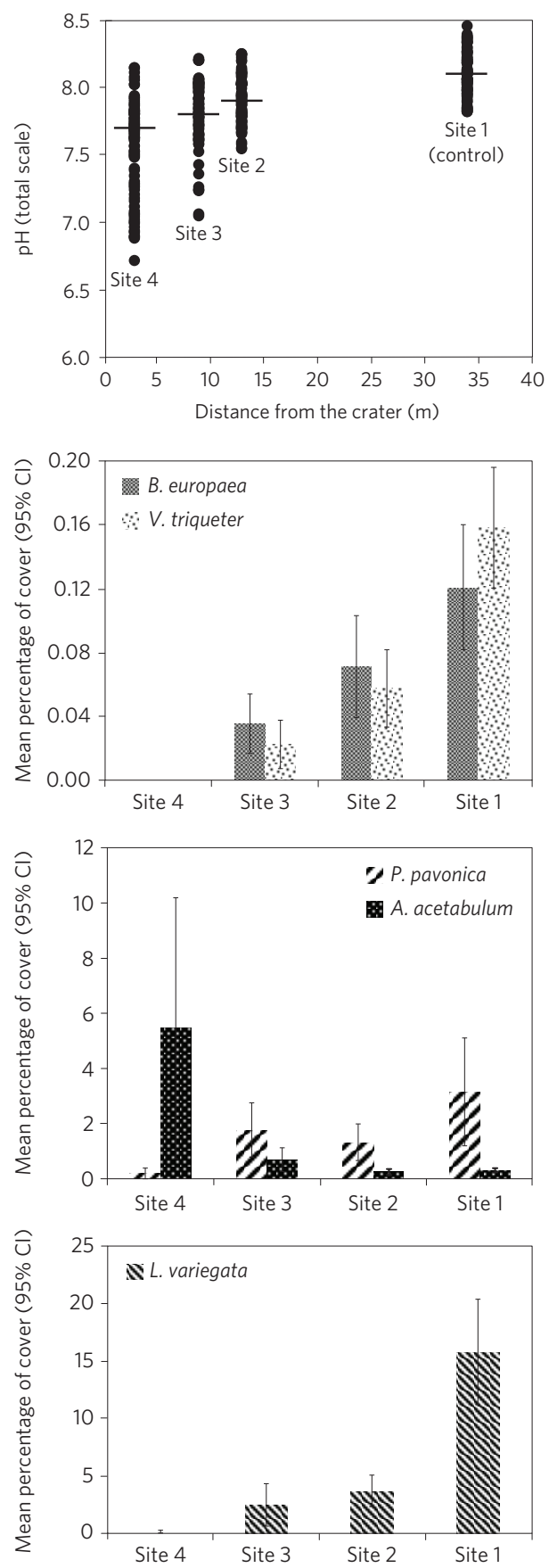

Figure 1 | Range in $\mathrm{pH}$ total scale and mean percentage of cover for Balanophyllia europaea, Vermetus triqueter, Padina pavonica, Acetabularia acetabulum and Lobophora variegata along the $\mathrm{pCO}_{2}$ gradient. $\mathrm{pH}$ measures were 103-110 per site. Horizontal bars indicate the median $\mathrm{pH}$. Error bars are $95 \%$ confidence intervals $(\mathrm{Cl})$.

nuclear magnetic resonance analyses. $B$. europaea skeletons have already been found to increase their porosity in stress conditions, such as increasing temperature ${ }^{14}$.

The apical regions of $V$. triqueter shell-tubes of similar diameter $(\sim 5 \mathrm{~mm})$ were analysed. Aragonite was the only mineral phase (Supplementary Fig. 2). Shell-tubes from Site 1 had four layers with different crystal texture and variable relative thickness among samples (Fig. 2). The first two layers were prismatic, with the second one made of regular prisms with a square section (500 $\mathrm{nm}$ side). The third was cross-lamellar with regular fibres $500 \mathrm{~nm}$ thick. The fourth external layer was spherulitic, with several bores and channels (Fig. 2). In one of six samples from Site 2, and in four of six from Site 3, the two internal layers were not present. Different hardnesses and elastic Young's moduli were associated with different textures, without significant variations among Sites (Supplementary Table 2). Organic matrix content was homogeneous among Sites (Kruskal-Wallis test, $p>0.05$; Table 1 and Supplementary Fig. 3). The unaffected mineralogy of $V$. triqueter shell-tubes is possibly due to the exquisite control of biological macromolecules on mollusc mineralization, which occurs in confined sites resulting in complex crystalline textures (Fig. 2). During shell-tube growth, the external layers are the first to be deposited, followed by the internal ones ${ }^{11}$. A $\mathrm{pH}$ reduction can reduce the growth rates (calcification) of mollusc shells ${ }^{15}$, which probably explains the absence of the internal layers in shell-tubes from the most acidic Sites.

Padina pavonica thallus tips from Site 1 were mainly aragonitic with traces of hydrate calcium sulphate salts (CSh). Aragonite concentration decreased with increasing $p \mathrm{CO}_{2}$, and almost only CSh was observed at Site 4 (Supplementary Fig. 2). The presence of CSh was investigated in detail by further tests and considerations (Supplementary Information). The overall mineral content differed among Sites (Kruskal-Wallis test, $p<0.05$; Table 1 and Supplementary Fig. 3), and declined with increasing $p \mathrm{CO}_{2}$ (Spearman's rho of the correlation with $\mathrm{pH}=0.592, p<0.01$ ). In all samples, many aragonite needle-like crystals were aggregated or merged forming bundles. CSh crystals appeared as prisms or tablets (Fig. 3 and Supplementary Fig. 6). The decalcification left the thalli free of mineral deposits (Supplementary Fig. 6). In P. pavonica, CSh increased with increasing $p \mathrm{CO}_{2}$. Some stabilization of CSh salts by algal molecules ${ }^{16,17}$, probably polysaccharides, is expected, as in sea water CSh converts to gypsum.

Acetabularia acetabulum was mainly aragonitic, with minor presence of whewellite (Supplementary Fig. 2). All samples contained about $10 \%(\mathrm{w} / \mathrm{w})$ of water. The content of mineral phases, estimated after pyrolysis and release of water, differed among Sites (Kruskal-Wallis test, $p<0.01$; Table 1 and Supplementary Fig. 3) and declined with increasing $p \mathrm{CO}_{2}$ (Spearman's rho of the correlation with $\mathrm{pH}=0.555, p<0.01$ ). The aragonite/whewellite ratio decreased with increasing $p \mathrm{CO}_{2}$. Globular granules of amorphous material rich in $\mathrm{Ca}$ and $\mathrm{S}$ were observed on the surface of needle-like aragonite aggregates at Sites 1-4 (Fig. 3 and Supplementary Fig. 6). Whewellite was the only phase detected at Site 4 (Fig. 3 and Supplementary Fig. 2), where it appeared as prisms. After decalcification, the cup surface was free of mineral deposits (Supplementary Fig. 6). In line with a mainly chemical mineralization control ${ }^{17}$, increasing $p \mathrm{CO}_{2}$ did not affect deposition of whewellite in $A$. acetabulum. The persistence of amorphous globular particles rich in calcium and sulphur was unexpectedly observed when aragonite disappeared. This phase, soluble in acetic acid solution, may be the result of interactions between $\mathrm{Ca}$ ions and the sulphonated groups of polysaccharides.

Within each sample, $P$. pavonica and $A$. acetabulum showed a marked reduction of mineralized areas with increasing $p \mathrm{CO}_{2}$ (Fig. 4). Their aragonite content decreased with decreasing $\Omega_{\text {arag. }}$. At a $\Omega_{\text {arag }}$ of 1.5 , aragonite was not observed, probably because this saturation level is too low to sustain its nucleation process. The observed changes in morphology of aragonite crystals (Fig. 3) are associated with seawater chemistry ${ }^{18}$.

The percentage of cover for all species, except $A$. acetabulum, differed among Sites (Kruskal-Wallis test, $p<0.001$ ), and decreased with increasing $\mathrm{pCO}_{2}$ (Supplementary Table 3). B. europaea and $V$. triqueter were not found at Site $4\left(\mathrm{pH}=7.7, \Omega_{\mathrm{arag}}=1.5\right.$; Fig. 1). Densities of $A$. acetabulum were homogeneous among Sites (Kruskal-Wallis test, $p>0.05$ ). This suggests that $P$. pavonica and $A$. acetabulum are not obligate calcifiers, persisting in high $\mathrm{pCO}_{2}$ where also the non-calcifying species L. variegata survives (Fig. 1). 
Table 1| Summary of the main effects of ocean acidification on the mineral distribution and content in the calcified organisms with increasing proximity to the $\mathrm{CO}_{2}$ seep (declining $\mathrm{pH}$ ).

\begin{tabular}{lllllllllll} 
& & & \multicolumn{2}{c}{ Balanophyllia europaea } & \multicolumn{2}{c}{ Vermetus triqueter } & & \multicolumn{2}{c}{ Padina pavonica } & \multicolumn{2}{c}{ Acetabularia acetabulum } \\
\hline & $\begin{array}{l}\text { Median } \\
\text { pH }\end{array}$ & $\begin{array}{l}\text { Median } \\
\boldsymbol{\Omega}_{\text {arag }}\end{array}$ & $\begin{array}{l}\text { Mineral } \\
\text { phase }\end{array}$ & $\begin{array}{l}\text { Mineral } \\
\text { phase (\%) }\end{array}$ & $\begin{array}{l}\text { Min } \\
\text { phase }\end{array}$ & $\begin{array}{l}\text { Mineral } \\
\text { phase (\%) }\end{array}$ & $\begin{array}{l}\text { Mineral } \\
\text { phases }\end{array}$ & $\begin{array}{l}\text { Mineral } \\
\text { phases (\%) }\end{array}$ & $\begin{array}{l}\text { Mineral } \\
\text { phases* }\end{array}$ & $\begin{array}{l}\text { Mineral } \\
\text { phases (\%) }\end{array}$ \\
\hline Site 1 & 8.1 & 3.6 & A & $97.4 \pm 0.4$ & A & $98.0 \pm 0.5$ & A CSh & $73.9 \pm 8.3$ & A Wh & $42.9 \pm 3.9$ \\
Site 2 & 7.9 & 2.4 & A & $97.80 \pm 0.04$ & A & $98.3 \pm 0.2$ & A CSh & $71.5 \pm 10.6$ & A Wh & $24.2 \pm 6.9$ \\
Site 3 & 7.8 & 2.1 & A & $97.8 \pm 0.2$ & A & $98.1 \pm 0.1$ & A CSh & $59.6 \pm 4.9$ & A Wh & $22.7 \pm 7.6$ \\
Site 4 & 7.7 & 1.5 & - & - & - & - & A CSh & $61.6 \pm 4.5$ & Wh & $25.4 \pm 8.0$ \\
\hline
\end{tabular}

Uncertainties are one standard deviation. A, Wh and CSh indicate aragonite, whewellite and monohydrate calcium sulphate salts. The percentage of mineral phase(s) is reported as mass ratio.

${ }^{*}$ Amorphous globular particles were also detected. ${ }^{\dagger}$ The content of organic matrix is the complement to 100 in $B$. europaea and $V$. triqueter where no significant amounts of water were detected in the skeletons and shell-tubes. P. pavonica and A. acetabulum contained a significant amount of bounded water and their percentage of organic matrix significantly increased with $p \mathrm{CO}_{2} .{ }^{\ddagger}$ This phase was detected in traces. When two phases were present, the most abundant one is indicated in bold.
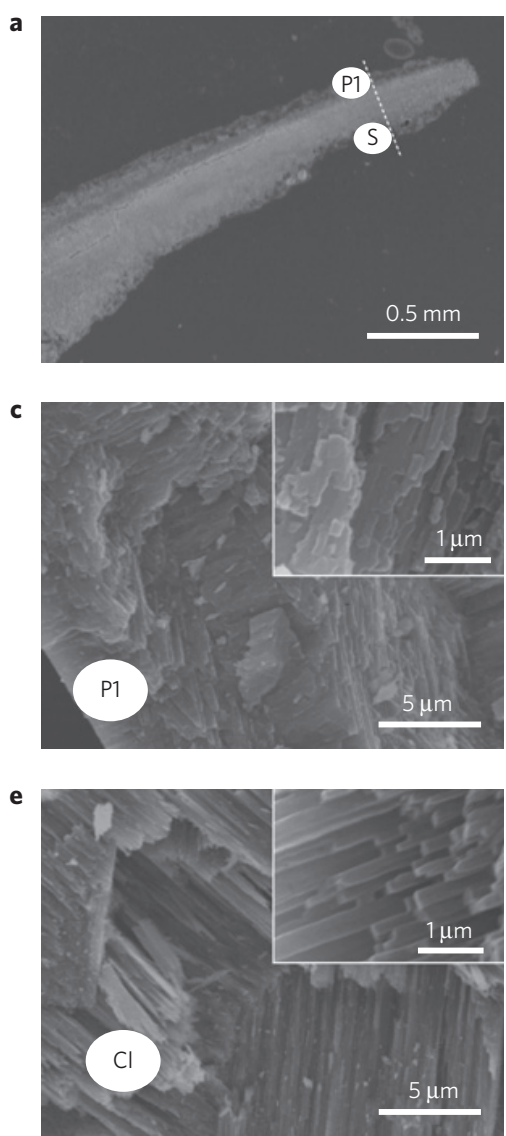
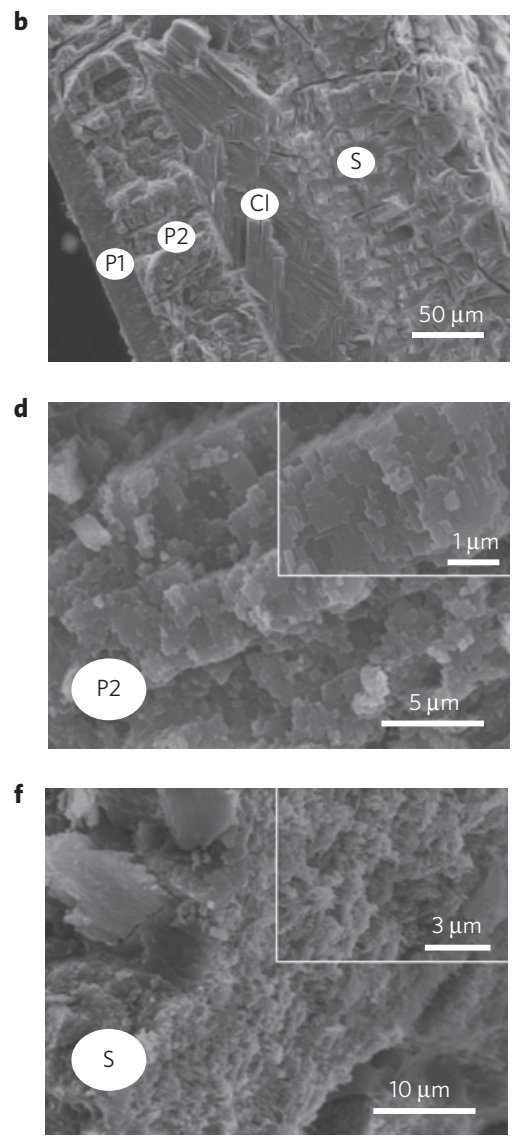

Figure 2 | Scanning electron microscope images of a longitudinal section of Vermetus triqueter shell-tube. a, Apical region of shell-tube.

High-magnification images were taken along the dotted line from inside (P1) to outside (S) the tube. b, Shell-tubes in Site 1 consisted of four layers (P1, P2, $\mathrm{Cl}, \mathrm{S}$ ). c, First prismatic layer (P1). d, Second prismatic layer (P2), with square cross-sections. e, Cross-lamellar layer (CI). f, Spherulitic layer (S) containing bores and channels. The first two layers were not present in one sample from Site 2 and in most of the samples from Site 3.

A changing benthic community was associated with the $\mathrm{pCO}_{2}$ gradient (Supplementary Video). The coverage of a coral, a mollusc, and two macroalgae, one of which is a calcifier, declined with increasing $p \mathrm{CO}_{2}$ (Fig. 1). This is in agreement with previous investigations at $\mathrm{CO}_{2}$ vents, documenting marked reductions in calcifying macroalgal abundance $e^{7,8}$. Calcifying organisms seem the most sensitive to elevated $p \mathrm{CO}_{2}$ (ref. 19), even if their response is not consistent ${ }^{8,15,20}$. A. acetabulum, B. europaea and $V$. triqueter were previously found only outside vent areas, at a $\mathrm{pH}_{\mathrm{TS}}$ of 8.14 (ref. 7). Instead, in our survey $B$. europaea and $V$. triqueter survived up to $\mathrm{pH}_{\mathrm{TS}} 7.8$ and algal species up to $\mathrm{pH}_{\mathrm{TS}} 7.7$ (Fig. 1). The response of macroalgae to $\mathrm{pCO}_{2}$ is expected to vary among species. As an example, increased cover with decreasing $\mathrm{pH}$ was observed for Padina spp. at $\mathrm{CO}_{2}$ seeps in Vulcano and Papua New Guinea ${ }^{21}$, and for L. variegata at $\mathrm{CO}_{2}$ seeps in Ischia ${ }^{10}$, which contrasts with our data. The response of non-calcifying macroalgae to elevated $p \mathrm{CO}_{2}$ is variable ${ }^{22}$, depending on energy availability ${ }^{23}$. The nature of $\mathrm{CO}_{2}$-induced shifts in macroalgal community structure is likely to vary depending on other environmental factors, such as nutrient availability, temperature and solar radiation ${ }^{24}$. For instance, L. variegata were sampled in Ischia at $1 \mathrm{~m}$ depth and in our study at 8-12 $\mathrm{m}$. Growth of the brown alga Dictyota ciliolata decreases with decreasing light intensity ${ }^{25}$. In the brown alga Fucus vesiculosus, photosynthesis and growth decrease with increasing depth ${ }^{26}$ from 
a
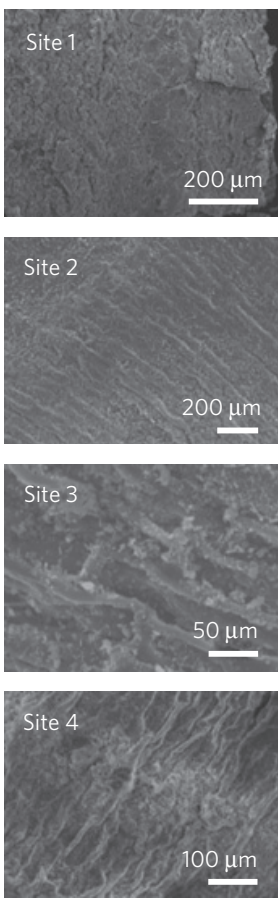

Padina pavonica
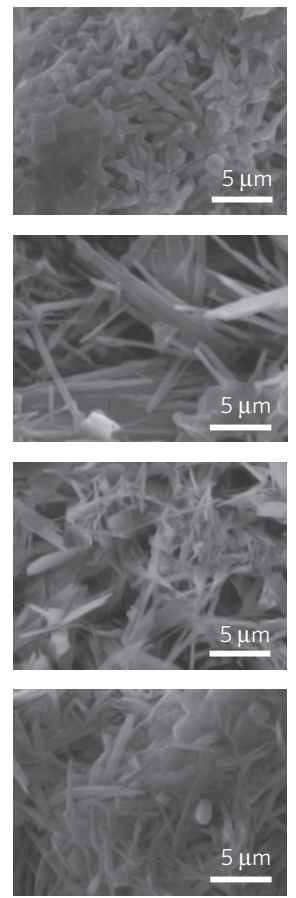

b
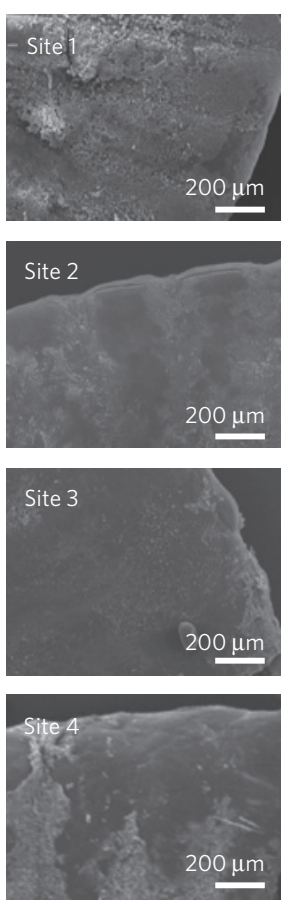
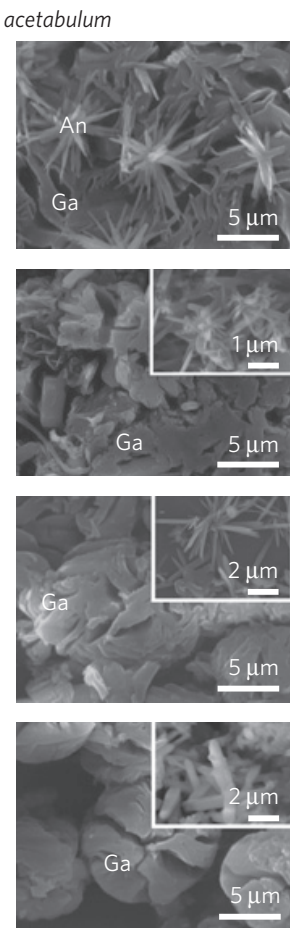

Figure 3 | Scanning electron microscope images of Padina pavonica thalli and Acetabularia acetabulum cups. a,b, Low-magnification (left column) and high-magnification (right column) images. P. pavonica (a) became less mineralized with increasing $p \mathrm{CO}_{2}$. The aggregation and shape of aragonite crystals

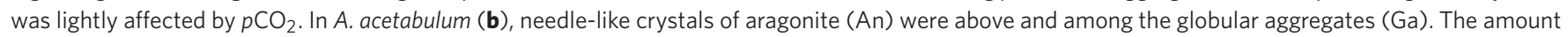
of biomineralized material was reduced with increasing $\mathrm{pCO}_{2}$, whereas the centre of the cup became more populated by spherical aggregates. Aragonite needles are shown in the inset for Site 2 and 3, and whewellite is shown in the inset for Site 4.

1 to $6 \mathrm{~m}$. At the high light of the shallow Ischia site, L. variegata may compensate for the negative effect of lowered $\mathrm{pH}$ through enhanced growth.

We related the biological control over biomineralization with changes in the abundance of organisms along natural $p \mathrm{CO}_{2}$ gradients. The content of biomineralized products decreased with increasing $p \mathrm{CO}_{2}$ only in the two calcifying algal species (with a weak control over their biomineralization), but the two species with

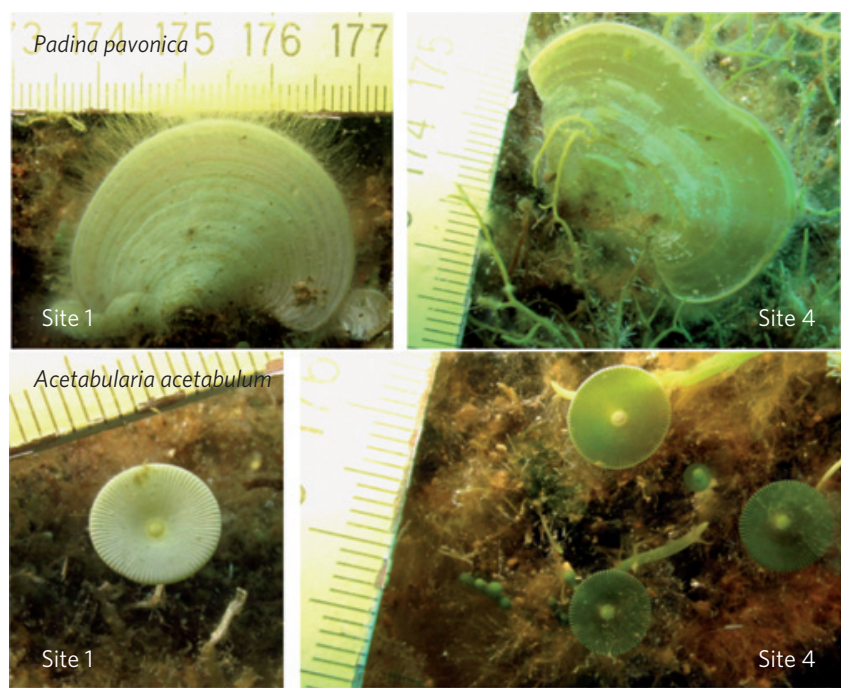

Figure 4 | In situ pictures of Padina pavonica and Acetabularia acetabulum at Sites 1 and 4, showing the reduction of calcified material (white areas) with increasing $p \mathrm{CO}_{2}$. A ruler is included in each image to show scale. The smallest tick marks indicate a length of $1 \mathrm{~mm}$. stronger biomineralization control (B. europaea and $V$. triqueter) tolerated less severe $\mathrm{pCO}_{2}$ increases $(\mathrm{pH}$ 7.8) than the algae $(\mathrm{pH} \leq 7.7)$. Moreover, the more tolerant algae continued to grow despite their biomineralization products being profoundly altered by $p \mathrm{CO}_{2}$. Even if biomineralization in algae is only induced ${ }^{17}$, we cannot exclude that the switch from aragonite to other biominerals may represent a phenomenon of phenotypic plasticity ${ }^{27}$, which is increasingly being found to strongly contribute to persistence in the face of climate change ${ }^{28}$. The control over biomineralization may not be the only cause of the observed differences, because the coral and the mollusc have a biology completely dependent on calcification, whereas the algae do not. Moreover, the algae may benefit from $p \mathrm{CO}_{2}$ increase in terms of photosynthesis, whereas the coral may be less dependent on the photosynthetic process and the mollusc does not photosynthesize. This study adds new evidence to field studies on ocean acidification effects ${ }^{4,9,29,30}$, all indicating major ecological shifts as $\mathrm{CO}_{2}$ rises. It documented that the mineralization response to ocean acidification seems connected with the organisms' control of biomineralization, increasing $p \mathrm{CO}_{2}$ profoundly affects the abundance of many benthic organisms, and only the species with weaker control were observed at the lowest $\mathrm{pH}$.

\section{Methods}

Study site. Fieldwork was conducted at Panarea, Italy (Supplementary Video and Fig. 1), where hydrothermally stable $\mathrm{CO}_{2}$ emissions acidify sea water, generating a $\mathrm{pH}$ gradient (see Supplementary Information for details).

Carbonate chemistry. Four sampling Sites were selected (Fig. 1 and Supplementary Fig. 1): a control site (Site 1), two intermediate $\mathrm{pCO}_{2}$ sites (Site 2 and Site 3), and a high $\mathrm{pCO}_{2}$ site (Site 4). pH (NBS scale), temperature and salinity were measured at each Site during several surveys between July 2010 and May 2013 with a multi-parametric probe (600R, YSI Incorporated) powered from a small boat and operated by SCUBA divers. Bottom-water samples for determination of total alkalinity were collected and analysed using standard methods 
(see Supplementary Information for details). Further temperature data were recorded every three hours by sensors (Thermochron iButton, DS1921G, Maxim Integrated Products) attached in each Site from July 2010 to May 2013. Measured $\mathrm{pH}$ was converted to the total scale using CO2SYS software. Median $\mathrm{pH}$ (backtransformed hydrogen ion concentrations) were calculated for each Site. The $\mathrm{pH}$, total alkalinity, salinity and temperature were used to calculate other carbonate system parameters using the software CO2SYS (Supplementary Information).

Benthic survey. Photographs of benthos ( 5 to 10 per Site, $50 \times 50 \mathrm{~cm}$ for the animals, $21.0 \times 29.7 \mathrm{~cm}$ for the algae) were used to measure the percentage of cover for B. europaea, V. triqueter, P. pavonica, A. acetabulum and L. variegata at each Site. See Supplementary Information for details.

Vent gas. Gas was sampled during five surveys (June 2011-May 2013) and analysed at the Laboratory of Fluid and Rock Geochemistry of the University of Florence using standard methods (Supplementary Information). Water samples were collected and tested for dissolved $\mathrm{H}_{2} \mathrm{~S}$ (Supplementary Information).

Statistical analyses. Analysis of variance and the post hoc Fisher least significant difference test were used to test for differences among Sites using arcsine and log-transformation for percentage of cover and environmental data, respectively, when necessary. Otherwise, the non-parametric Kruskal-Wallis and Spearman's rank correlation coefficients were used. All analyses were performed using SPSS v.20.

Biomineralization. Samples were randomly collected by SCUBA divers at all Sites and were prepared for analyses with standard methods (Supplementary Information). Microscopic observations and mechanical and spectroscopic measurements required the preparation of cross-sections of the samples (Supplementary Information). X-ray powder diffraction and Fourier transform infrared spectroscopy patterns on small amounts of powdered samples were collected using standard methods (Supplementary Information). Attenuated total reflection Fourier transform infrared spectra of sample cross-sections were acquired with standard methods (Supplementary Information). The organic matter content in the sample was determined by thermogravimetric analysis (Supplementary Information). Microstructures were observed using optical and scanning electronic microscopes (SEM; Supplementary Information). The mechanical properties of shell-tubes and skeletons were measured with standard nano-indentation techniques (Supplementary Information).

Received 12 December 2013; accepted 7 April 2014; published online 25 May 2014

\section{References}

1. IPCC, IPCC Special Report on Renewable Energy Sources and Climate Change Mitigation (Cambridge Univ. Press, 2011).

2. Orr, J. C. et al. Anthropogenic ocean acidification over the twenty-first century and its impact on calcifying organisms. Nature 437, 681-686 (2005).

3. Fabry, V. J., Seibel, B. A., Feely, R. A. \& Orr, J. C. Impacts of ocean acidification on marine fauna and ecosystem processes. ICES J. Mar. Sci. 65, 414-432 (2008).

4. Rodolfo-Metalpa, R., Martin, S., Ferrier-Pages, C. \& Gattuso, J. P. Response of Mediterranean corals to ocean acidification. Biogeosciences Discuss. 6, 7103-7131 (2010).

5. Hahn, S. et al. Marine bivalve shell geochemistry and ultrastructure from modern low $\mathrm{pH}$ environments: environmental effect versus experimental bias. Biogeosciences 9, 1897-1914 (2012).

6. Barry, J. P., Hall-Spencer, J. M. \& Tyrrell, T. Guide to Best Practices for Ocean Acidification Research and Data Reporting (Publications Office of the European Union, 2010)

7. Hall-Spencer, J. M. et al. Volcanic carbon dioxide vents show ecosystem effects of ocean acidification. Nature 454, 96-99 (2008).

8. Fabricius, K. E. et al. Losers and winners in coral reefs acclimatized to elevated carbon dioxide concentrations. Nature Clim. Change 1, 165-169 (2011).

9. Cigliano, M., Gambi, M. C., Rodolfo-Metalpa, R., Patti, F. P. \& Hall-Spencer, J. M. Effects of ocean acidification on invertebrate settlement at volcanic $\mathrm{CO}_{2}$ vents. Mar. Biol. 157, 2489-2502 (2010).

10. Porzio, L., Buia, M. C. \& Hall-Spencer, J. M. Effects of ocean acidification on macroalgal communities. J. Exp. Mar. Biol. Ecol. 400, 278-287 (2011).

11. Lowenstam, H. A. \& Weiner, S. On Biomineralization (Oxford Univ. Press, 1989).

12. Holcomb, M., Cohen, A. L., Gabitov, R. I. \& Hutter, J. L. Compositional and morphological features of aragonite precipitated experimentally from seawater and biogenically by corals. Geochim. Cosmochim. Acta 73, 4166-4179 (2009).
13. Venn, A. A. et al. Impact of seawater acidification on $\mathrm{pH}$ at the tissue-skeleton interface and calcification in reef corals. Proc. Natl Acad. Sci. USA 110, 1634-1639 (2013).

14. Fantazzini, P. et al. A time-domain nuclear magnetic resonance study of Mediterranean scleractinian corals reveals skeletal-porosity sensitivity to environmental changes. Environ. Sci. Technol. 47, 12679-12686 (2013).

15. Ries, J. B., Cohen, A. L. \& McCorkle, D. C. Marine calcifiers exhibit mixed responses to $\mathrm{CO}_{2}$-induced ocean acidification. Geology 37, 1131-1134 (2009).

16. McCandless, E. L. \& Craigie, J. S. Sulfated polysaccharides in red and brown algae. Ann. Rev. Plant Physiol. 30, 41-53 (1979).

17. Mann, S., Webb, J. \& Williams, R. J. P. Biomineralization: Chemical and Biochemical Perspectives (VCH Verlagsgesellschaft, 1989).

18. Robbins, L. L., Knorr, P. O. \& Hallock, P. Response of Halimeda to ocean acidification: field and laboratory evidence. Biogeosci. Discuss. 6, 4895-4918 (2009).

19. Kroeker, K. J., Kordas, R. L., Crim, R. N. \& Singh, G. G. Meta-analysis reveals negative yet variable effects of ocean acidification on marine organisms. Ecol. Lett. 13, 1419-1434 (2010).

20. Fabry, V. J. Marine calcifiers in a high- $\mathrm{CO}_{2}$ ocean. Science 320, 1020-1022 (2008).

21. Johnson, V. R., Russell, B. D., Fabricius, K. E., Brownlee, C. \& Hall-Spencer, J. M. Temperate and tropical brown macroalgae thrive, despite decalcification, along natural $\mathrm{CO}_{2}$ gradients. Glob. Change Biol. 18, 2792-2803 (2012).

22. Cornwall, C. E. et al. Carbon-use strategies in macroalgae: Differential responses to lowered $\mathrm{pH}$ and implications for ocean acidification. J. Phycol. 48, 137-144 (2012).

23. Hofmann, L. C., Straub, S. \& Bischof, K. Competition between calcifying and noncalcifying temperate marine macroalgae under elevated $\mathrm{CO}_{2}$ levels. Mar. Ecol. Prog. Ser. 464, 89-105 (2012).

24. Sarker, M. Y., Bartsch, I., Olischläger, M., Gutow, L. \& Wiencke, C. Combined effects of $\mathrm{CO}_{2}$, temperature, irradiance and time on the physiological performance of Chondrus crispus (Rhodophyta). Bot. Mar. 56, 63-74 (2013).

25. Cronin, G. \& Hay, M. E. Effects of light and nutrient availability on the growth, secondary chemistry, and resistance to herbivory of two brown seaweeds. Oikos 77, 93-106 (1996).

26. Rohde, S., Hiebenthal, C., Wahl, M., Karez, R. \& Bischof, K. Decreased depth distribution of Fucus vesiculosus (Phaeophyceae) in the Western Baltic: Effects of light deficiency and epibionts on growth and photosynthesis. Eur. J. Phycol. 43, 143-150 (2008).

27. Munday, P. L., Warner, R. R., Monro, K., Pandolfi, J. M. \& Marshall, D. J. Predicting evolutionary responses to climate change in the sea. Ecol. Lett. 16, 1488-1500 (2013).

28. Anderson, J. T., Inouye, D. W., McKinney, A. M., Colautti, R. I. \& Mitchell-Olds, T. Phenotypic plasticity and adaptive evolution contribute to advancing flowering phenology in response to climate change. Proc. R. Soc. B 279, 3843-3852 (2012).

29. Dias, B. B., Hart, M. B., Smart, C. W. \& Hall-Spencer, J. M. Modern seawater acidification: The response of foraminifera to high- $\mathrm{CO}_{2}$ conditions in the Mediterranean Sea. J. Geol. Soc. 167, 843-846 (2010).

30. Calosi, P. et al. Distribution of sea urchins living near shallow water $\mathrm{CO}_{2}$ vents is dependent upon species acid-base and ion-regulatory abilities. Mar. Pollut. Bull. 73, 470-484 (2013).

\section{Acknowledgements}

I. Berman-Frank helped with alkalinity measurements. B. Basile, F. Sesso, and Eolo Sub diving centre assisted in the field. F. Gizzi and G. Polimeni helped during preparation and participated in field surveys. The Scientific Diving School supplied scientific, technical and logistical support. The research leading to these results has received funding from the European Research Council under the European Union's Seventh Framework Programme (FP/2007-2013)/ERC Grant Agreement no. [249930 - CoralWarm]

\section{Author contributions}

S.G., Z.D. and G.F. conceived and designed research. S.G., F.P., E.C. and B.C. collected the samples and performed the diving fieldwork. L.P., S.F., M.R. and G.F. performed the laboratory experiments. S.G., F.P., E.C., B.C., L.P., P.F., M.R., K.E.F. and G.F. analysed the data. All authors wrote the manuscript and participated in the scientific discussion.

\section{Additional information}

Supplementary information is available in the online version of the paper. Reprints and permissions information is available online at www.nature.com/reprints. Correspondence and requests for materials should be addressed to S.G. or G.F.

\section{Competing financial interests}

The authors declare no competing financial interests. 